\title{
Techniques for Measuring Attitudinal Learning Outcomes in Computer Science and Engineering
}

\author{
Bruce Mathew ${ }^{1, *}$, Mohamed Elfateeh Algamar Ismail ${ }^{2}$, Sathyendra Bhat J. ${ }^{3}$ \& Dr. T. Gnana Sambanthan ${ }^{4}$ \\ ${ }^{I}$ Research Scholar, Dept of CSE, NITTTR, University of Madras, Chennai, TN, India. \\ ${ }^{2}$ Research Scholar, Dept of CSE, NITTTR, University of Madras, Chennai, TN, India. \\ ${ }^{3}$ Assistant Professor, St Josephs College of Engineering, Mangalore, Karnataka, India. \\ ${ }^{4}$ Retd Prof., Dept of CSE, NITTTR, Taramani, Chennai, TN, India. \\ *Corresponding Author: Bruce Mathew \\ ORCID: 0000-0002-0952-7170 (Bruce Mathew)
}

\begin{abstract}
Higher education globally, particularly the Computer Science and Engineering (CSE) in India is shifting to Outcome Based Education (OBE) which is an educational philosophy/theory that stresses on what a student would be able to do after an educational experience. Learning Outcomes (LOs), an important component of OBE are the actual measurable outcomes of any instructional event. Skill and attitudinal LOs are needed to be imbibed into domain dependent subject specific content, as per the principles of OBE. The paper elaborates experimental procedures in demonstrating techniques for imbibing 'Ethics', 'Engineer and Society' and 'Problem solving' the three delimited abilities as LOs. They are three of the 12 standards formulated by the Washington accord, as graduate attributes. The main objective of the paper is to demonstrate techniques for imbibing the three chosen competencies. Experimental methodologies were adopted and survey methods were used for validation of the studies. The domain considered for the experiments is 'Operating System', an important course of the CSE. Cognitive structure, a schema with mental constructs (pedagogical aspect), that uses knowledge structures which are logically organized instructional contents, is demonstrated by the experiments. Instructionally proved terms/phrases of chosen LOs along with the chosen domain dependent terms are integrated that imbibed the required skill and attitudinal competencies. Survey methods were adapted for executing the experiments with experimental group of student respondents and validated with teacher respondents. Conclusions are drawn, which will be of immense use to CSE educators and researchers.
\end{abstract}

Keywords: Engineering Education, Knowledge and Cognitive Structure, Learning Outcome, Outcome Based Education; Skill and Attitudinal Competency.

\section{INTRODUCTION AND BACKGROUND}

The new education policy of Govt. of India (NPE, 2017) has promulgated certain strategies for taking India further to knowledge power. Two of the strategies specify students' centred, flexible and holistic system of higher education, based on life skills for employability. This policy clearly emphasizes for quality improvement in higher education. Outcome Based Education (OBE) is an educational theory/philosophy which is grounded on maintaining, monitoring and improving the quality of (higher) education. Learning Outcomes (LOs), an important component of OBE are the actual measurable outcomes of any instructional event. LOs concentrate more on whether the students have learnt successfully (Driscoll, A et. al. 2007) and how well. Literature strongly confirms (Sue Bloxham, 2016, Driscoll, A et. al. 2007, Marki, 2012) learning outcomes, as one of the major requirements of continuous assessments. Continuous formative assessments and instructions are two sides of the same coin, as per the philosophy of OBE. Computer Science and Engineering (CSE), is one of the most sought-after programmes of the engineering education streams in India. In recent times, this CSE programme in the state of Kerala, India is moving towards OBE. This is a paradigm shift from the traditional, linear and examination driven content-based education system. Techniques imbibing LOs in instructions would direct the students towards holistic learning in a learner-centric upbringing (Shamsul Muhamad, et. al. 2012). Literature also indicates that various techniques are needed for measuring different types of students' learning-outcomes. Techniques must be developed through intensive research for specific learner and institutional characteristics. It should also be noted that LOs are related to subject (domain, like the CSE) specific pedagogy. Only specific, observable and measurable learning outcomes will show the expected results of learning. Learning outcomes may be categorized into skill based, behaviour (or attitude) based and domain dependent subject specific competencies. Abilities pertaining to these three categories should be imbibed while instructing the students so as to achieve effective holistic learning. These documented literatures indicate that imbibing these three competencies in the instructional contents is a huge challenge to educators. For example, how to integrate 'Problem solving' core capability in CSE with 'Ethics', an attitudinal competency and/or 'Modern 
tool usage', a hard skill ability? Effective instructions should allow measuring imbibed competencies of skills and attitudes (Karen E. Hinton, 2012). In view of the above, this particular (techniques for imbibing competencies) issue is considered as the main focus of this paper.

International Standards, defined as properties (or attributes) of graduated engineers, are specified by various accords, globally. The learning outcomes indicated above in terms of attitude, skill and the core competencies are termed as graduate attributes, by these standards. The Washington accord (Graduate Attributes, 1989) is the oldest amongst the accords. Three graduate attributes (out of the current 12) of the Washington accord are considered as case examples for this paper. They are: i. Ethics: Apply ethical principles and commitment to professional practices and engineering norms; ii. Engineer \& Society: Apply reasoning of contextual knowledge to socio economic issues through relevant professional engineering practices; iii. Problem Solving: Apply reasoning of contextual knowledge to socio economic issues through relevant professional engineering practices. These three competencies are considered as base for the proposed experiments in this paper.

It is convinced (Bruce Mathew et. al. 2018) that learning outcomes can be measured through direct or indirect assessment techniques. They can be used as indicators of longterm programme educational objectives of OBE. Portfolios such as feedbacks, periodical tests, assignments, group discussions and mini-project works would greatly assist the continuous formative assessments of learning outcomes. These concluding remarks which were drawn by our earlier works and the experimental results reported in this paper are part of a whole research program of the first author of this paper. This paper debates on two aspects for integrating the chosen competencies for deriving learning outcomes. The problem statements for the intended research studies are:

(i) Evolving suitable techniques, for imbibing these competencies in instructional contents and for continuous assessments.

(ii) How to validate the technique(s)?

(iii) What conclusions could be drawn?

With this background, the paper elaborates certain experimental studies and presents the results with observations for drawing conclusions. The conclusions will be of immense use to the researchers of CSE education and will also provide ample utility values for instructional designers.

\section{LITERATURE SUPPORT}

A CSE student is expected to have developed three domain related areas including mathematical, scientific and foundational engineering knowledge in his/her core contents. Along with these three, OBE stresses for skill and attitudinal competencies in an integrated fashion with the core. These competencies are required as graduate attributes to graduate as a full-fledged professional CS engineer (International Engineering Alliance, 2015). These graduate attributes
(Haidar, 2017) will be obtained in terms of measurable outcomes as they are the actual competencies that have been already attained by the graduates. Integration of these competencies in the teaching-learning processes of traditional linear method is not possible. These literatures and many more have concluded that attainments of LOs are possible only through OBE system.

A critical discussion on assessing unit outcomes between online and manual based systems has been documented (Shamsul Muhamad et. al. 2012). Certain competencies, apart from core related domains, such as communication, entrepreneurship and professionalism/ethics and, humanity have been discussed. These non-core competencies have been treated under the categories of psychomotor and affective domains respectively. Statements or descriptions of 'learning outcomes' should indicate end results of what a student would have achieved at the end of any instructional stage (Carriveau, Ronald S, 2016). The outcome achievements at every stage are made in statements, which are called Programme Outcomes (or POs or end outcomes) and Course Outcomes (or COs or unit outcomes). These literatures suggest that the instructional designer has to develop domain concepts along with LOs pertaining to the COs and POs.

It is stressed (Bruce Mathew et. al. 2019) that higher order competencies such as critical thinking ability in CSE could be measured in different perspectives. Two different instructional viewpoints are discussed, namely, i. the traditional linear timebound instructions and ii. Outcomes Based instructions, which have been tried out and the results documented. The objective of that exercise was to determine whether OBE with its instructional principles would be more suitable over the traditional methods in imbibing 'Critical thinking ability' as a learning outcome? Is it possible to classify students who prefer OBE methods of instructions? The paper elaborated experimental studies that compared and correlated the results obtained by these two selected instructional principles. The paper concluded that the students who practiced OBE are better than the traditional students, particularly in obtaining learning outcomes like 'critical thinking' ability. It is also concluded that articulating a domain dependent content for a critical situation is an important metric for measuring 'critical thinking' ability. Learning outcomes are measured on what the CSE students could actually do a CSE task to demonstrate what (s)he has learnt at the end of any learning event (Bruce Mathew et. al. 2020). However, the students might probably achieve the outcome in varying degrees of what was expected. Therefore, the learning outcomes should point out to what the teacher or instructional designer actually wanted the students to be able 'to do'.

Six components have been identified for imbibing learning outcomes in the core (Van der Horst et. al., 1997). They are however derived from the fundamental principles of OBE. But the methodologies that would be tried out in this paper by us are presented in italics. They are: (i) Specifying explicit learning outcomes of any selected standards (Washington accord); (ii) Flexibility in time-frame for mastering the skills for the students (experimentally try out with experimental students group); (iii) Varieties of instructional activities (depending upon learner characteristics of the experimental 
group); (iv) Criterion based assessments (using rubrics); (v) Qualifications (feed backing from teachers and learners) only on the demonstrated learning outcomes (delimiting to three types of competencies) and (vi) Flexible choice based programs (for the purpose of this research).

\section{INSTRUCTIONAL AND ASSESSMENT TECHNIQUES}

The objectives of the research studies include:

i. To try out imbibing phrases/terms pertaining to selective learning outcomes with domain dependent subject contents.

ii. To validate imbibed competencies by administering in assessments and surveys.

iii. To draw conclusions for research and utility values in CSE education.

\section{Demography for surveys:}

Convenient sampling has been adopted for the experiments (Sharma, B.A.V, 1988). Student respondents (from selective experimental group of an already formed core group): 24; Teacher respondents: 13 for validation. The samples belong to the CSE education streams of the Kerala State, India

\section{Integrating 'Ethics' and 'Engineer \& Society' in Problem Solving Core}

Proven verbs, phrases and terms (Gnana Sambanthan, T et. al, 2018, Carriveau, Ronald S, 2016) have been used as phrases/terms for specific LOs (in italics). Two real world tasks are used as the instrument for measuring core competencies imbibed with attitudinal/skill competencies. They are presented below. The domain core dependent words/terms belong to the course 'Operating System' of the lead discipline CSE, are imbibed.

1. Provide examples and rationale used to support your argument for the (international) success of PC brands, CPUs and OSs. Learning Outcome: "Acquiring (societal) bodies of information" under the graduate attribute: 'Engineer and Society'.

2. What is the reason that contributed to the success of Microsoft Operating system in the International markets? Learning Outcome: "Hypothesizing solution" under the graduate attribute: 'Problem solving ability'.

Results and Discussions on Students' Responses: The Cronbach's alpha for reliability has been checked with the student responses. Results obtained from the statistical analysis on reliability (Cronbach's alpha) are presented in Table 1.0.

\begin{tabular}{|c|l|c|c|}
\hline \multicolumn{4}{|c|}{ Table 1.0 Case Processing Summary } \\
\hline \multirow{3}{*}{ Cases } & Valid & N & $\%$ \\
\cline { 2 - 4 } & Excluded & 24 & 100.0 \\
\cline { 2 - 4 } & Total & 24 & 0.0 \\
\hline \multicolumn{2}{|c|}{ Reliability Statistics } \\
\hline \multicolumn{2}{|c|}{ Cronbach's Alpha } & \multicolumn{2}{c|}{ N of Items } \\
\hline \multicolumn{2}{|c|}{2} \\
\hline
\end{tabular}

The Cronbach's alpha value (Table 1.0) which is 0.831 clearly shows that the responses are reliable and valid. The statistical data for the experiment on students is given in Table 2.0.

The instruction and the subsequent assessment of it, for imbibing the 'Engineer and Society' in the instructional contents or in the results of the assessment, would form the purpose of this experiment in five stages. It was administered as a special instruction to the experimental group respondents. The design stages (presented below) were revealed to both the experimental group as well as to the teacher respondents. Feedbacks (scale values) were obtained for the five stages for validation. Marzano's phrases pertaining to specific cognitive structures (Marzano et. al. 2008) have been used for the experimental instructions.

Infusing 'Ethics' through taxonomies (Marzano et. al 2008)

Domain specific concept: "Analyse Device dependency vs. independency"

Learning outcome terms/phrases have been framed by educationists (Jonassen, D et. al, 1997, Marzano, et. al. 2007) and experimented with, for arriving at a useful manual (Gnana Sambanthan, et. al. 2018). Cognitive structure (Merrill, 2007) is a schema with mental constructs that uses knowledge structures or instructional contents. Cognitive structure provides meaning and organization to experiences and guides both the processing of new information and the retrieval of the stored information. The above literatures indicated that only through cognitive structures and knowledge structures that infused terms/words of LOs as well as domain terms could imbibe successfully. Thus, they are used for the experiments (instance of the instruction is shown in italics) and the imbibed competencies are instructed to the students.

- Cognitive structure: Analyse/Demonstrate [Infusion of 'Ethics'].

Identify a broader category of ..... differentiate between.... the problems of...identify the issues of.... [Learning outcome for Ethics: 'Forming concepts'] diagnose...what conclusions can be drawn [Learning outcome for Ethics: 'Convergent Problem Solving'] what inferences can be made [Learning outcome for Ethics: 'Applying Rules'] what would have happened [Learning outcome for Ethics: 'Reasoning from Concepts'].

- Cognitive structure: Knowledge Utilization/Application [Infusion of 'Problem solving abilities'].

Start working to connect different principles... acceptable standards [Learning outcome for Ethics: 'Applying Rules'].

- Cognitive structure: Final Integration [Infusion of 'Ethics'].

Move towards an ethically acceptable solution to the problem. 
International Journal of Engineering Research and Technology. ISSN 0974-3154, Volume 13, Number 9 (2020), pp. 2395-2401

(C) International Research Publication House. https://dx.doi.org/10.37624/IJERT/13.9.2020.2395-2401

\section{Questionnaire:}

Which stage of the instruction reliably represented ethical behaviour?

\section{$\underline{\text { Scale for measuring 'Ethics': }}$}

Highly represented: 4; Adequately represented: 3; Less than adequate: 2 ; Inadequate: 1 .

The methodology considered for the study is experimental in nature. Experiments are carried out by actually instructing a selected set of experimental group of students (24 respondents). The assessments are administered in different stages, starting from simple to complex on the students. The simplicity and complexity is revealed both in domain dependent terms as well as link words or those phrases provided by the literatures.

\section{RESULTS AND DISCUSSIONS}

Experiments with instructions and assessed results were subjected to statistical analyses. Survey methods administered have validated the techniques adopted. The standard deviation (and variance) of every experiment is shown and all the samples participated in the experiments. The mean, median and the mode have been presented. Reliability tests were conducted with Cronbach's alpha.

\section{Students' Responses:}

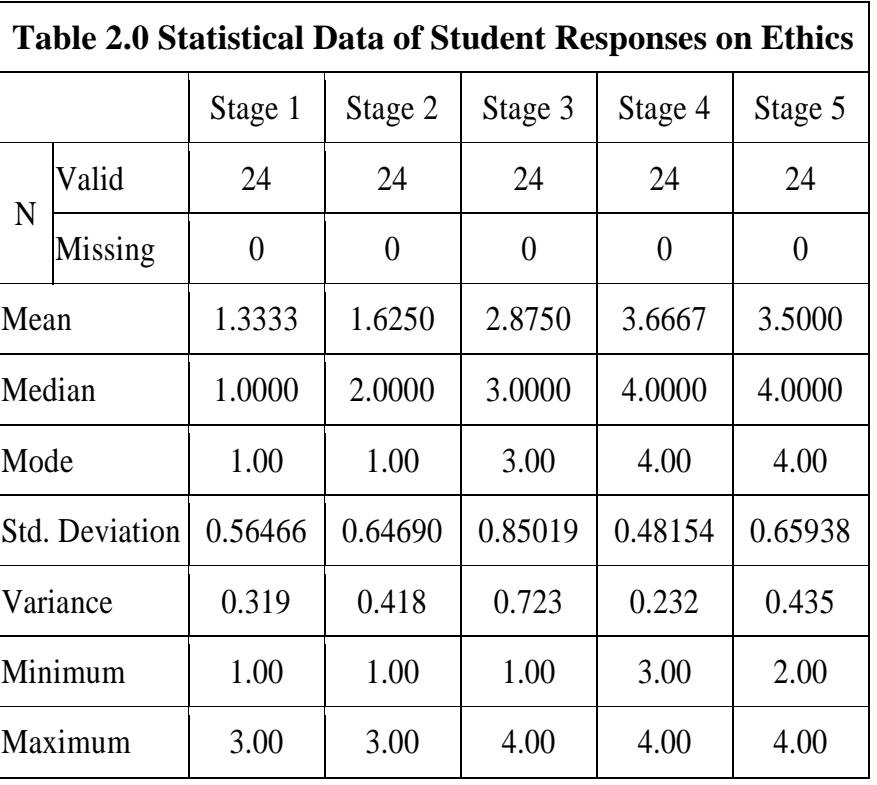

Table 2.0 clearly reveals that the first two stages have low median values namely 1.00 and 2.00 respectively. In fact, the mode values for these first two stages have the lower of 1.00. This tallied with the design of the first two stages. But as per the design the remaining three stages represented 'Ethics'. The third stage has 3.00 as median and mode as per Table 2.0. Stages 4 and 5 clearly show the median and mode values of the highest 4.00 . This tallied well with the design. The reliability of the survey is also tested and found that the Cronbach's value is seen to be as 0.787 as per Table 3.0.

\begin{tabular}{|c|l|c|c|}
\hline \multicolumn{4}{|c|}{ Table 3.0 Case Processing Summary \& } \\
\hline \multirow{3}{*}{ Cases } & Valid & N & $\%$ \\
\cline { 2 - 4 } & Excluded & 0 & 100.0 \\
\cline { 2 - 4 } & Total & 24 & 0.0 \\
\hline \multicolumn{3}{|c|}{ Reliability Statistics on Students } \\
\hline \multicolumn{2}{|c|}{ Cronbach's Alpha } & N of Items \\
\hline \multicolumn{2}{|c|}{5} \\
\hline
\end{tabular}

\section{Observation:}

The responses are clearly shown in the bar charts of Figure 1.0 for the first two stages. The two figures (left and right side) show lowest responses. The slightly higher opinion of the students showed for the second stage could be due to usage of pure domain words (Computer Science) that might indicate ethical usages in the real world.
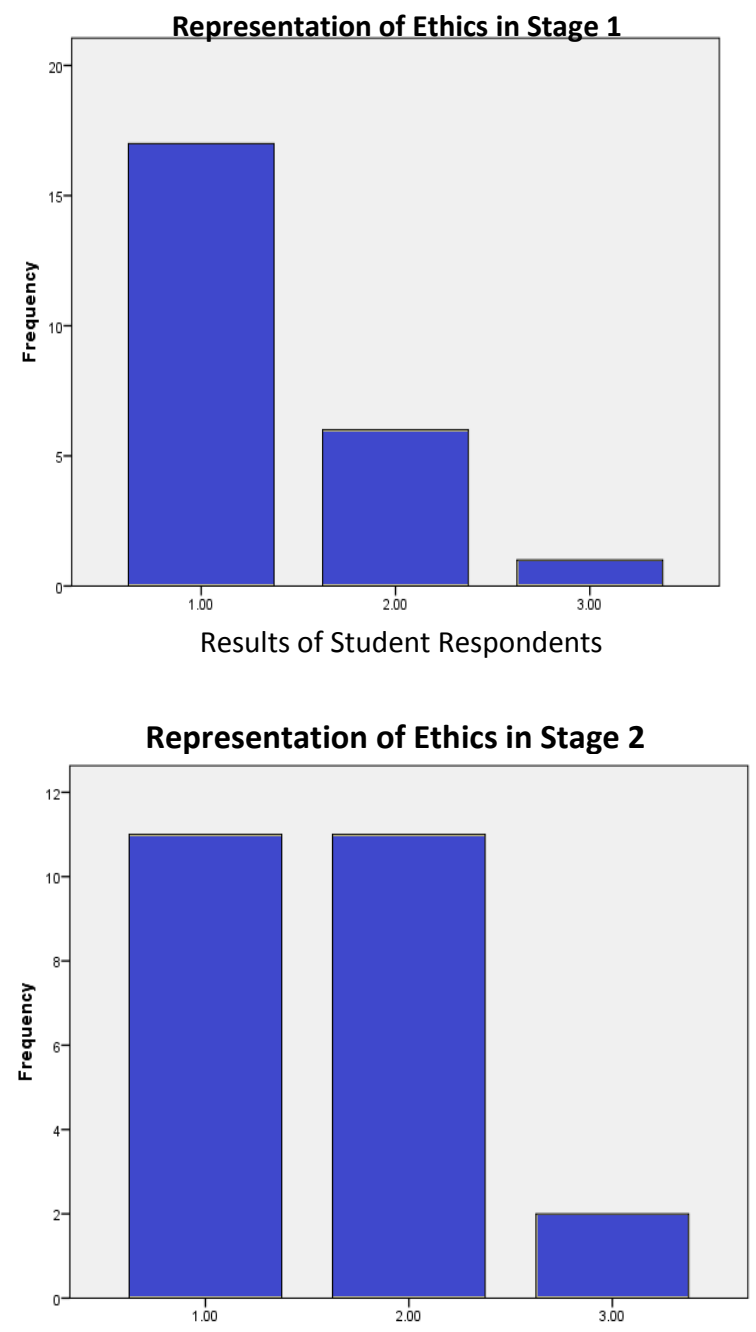

Results of Student Respondents

Figure 1.0 Students' Responses on Ethics in First Two Stages 


\section{Representation of Ethics in Stage 3}

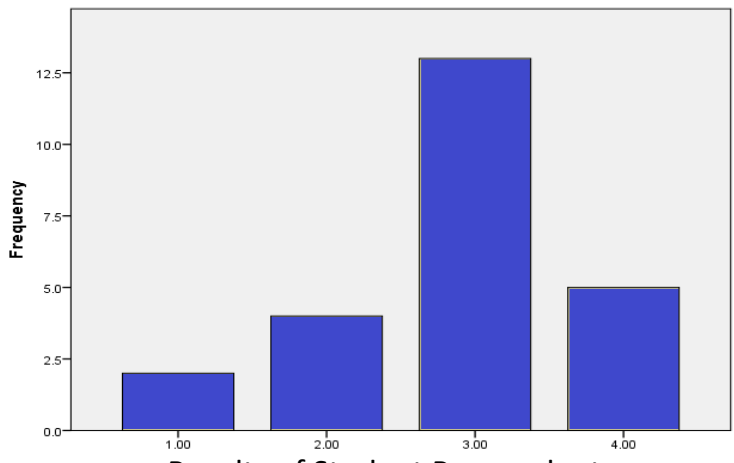

Results of Student Respondents

\section{Representation of Ethics in Stage 4}

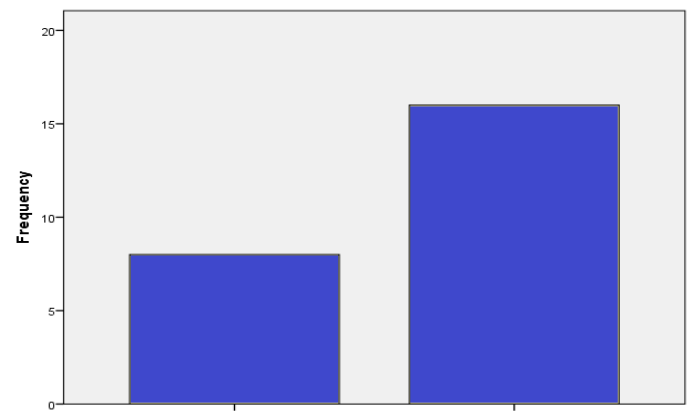

Results of Student Respondents

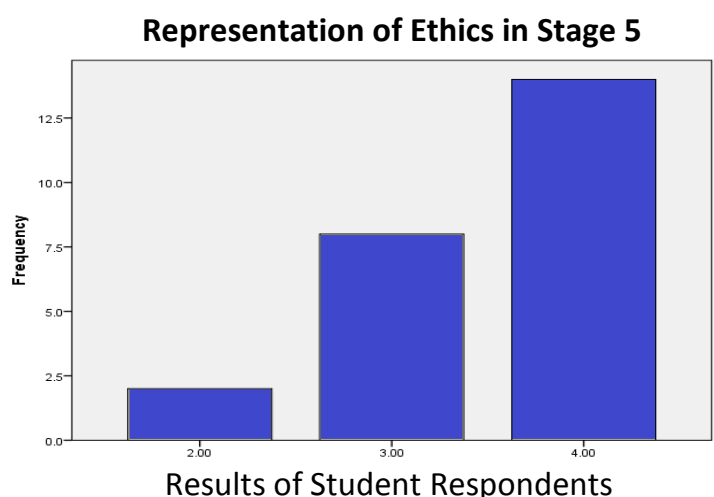

Figure 2.0 Students' Responses on Ethics in the Last Three Stages

In Figure 2.0, all the three stages represented ethical terms/phrases and the responses also agreed with the higher scale values (in all the three figures of Figure 2.0).

\section{Teachers' Responses:}

Table 4.0 presents statistical data on the survey conducted with teachers (respondents). The results are clearer than that of students. Table 4.0 clearly show lower values for the first two stages, namely 1.00 and 2.00 (median) and 1.00 as mode values for both these stages. Median and mode values are 4.00 same for all the remaining three stages. This exactly tallied with the design.

\begin{tabular}{|l|c|c|c|c|c|c|}
\hline \multicolumn{6}{|c|}{ Table 4.0 Statistical Data of Teacher Responses on Ethics } \\
\hline \multicolumn{2}{|l|}{} & Stage 1 & Stage 2 & Stage 3 & Stage 4 & Stage 5 \\
\hline \multirow{2}{*}{$\mathrm{N}$} & Valid & 13 & 13 & 13 & 13 & 13 \\
\cline { 2 - 7 } & Missing & 0 & 0 & 0 & 0 & 0 \\
\hline Mean & 1.3846 & 2.0000 & 3.5385 & 3.6923 & 3.8462 \\
\hline Median & 1.0000 & 2.0000 & 4.0000 & 4.0000 & 4.0000 \\
\hline Mode & 1.00 & $1.00^{\mathrm{a}}$ & 4.00 & 4.00 & 4.00 \\
\hline $\begin{array}{l}\text { Std. } \\
\text { Deviation }\end{array}$ & 0.50637 & 0.91287 & 0.66023 & 0.63043 & 0.37553 \\
\hline Variance & 0.256 & 0.833 & 0.436 & 0.397 & 0.141 \\
\hline Minimum & 1.00 & 1.00 & 2.00 & 2.00 & 3.00 \\
\hline Maximum & 2.00 & 3.00 & 4.00 & 4.00 & 4.00 \\
\hline
\end{tabular}

The responses are shown clearly through bar charts in Figures 3.0 and 4.0. As seen with students' responses teachers too have the feeling that 'Ethics' is not represented in the first two stages (Figure 3.0).

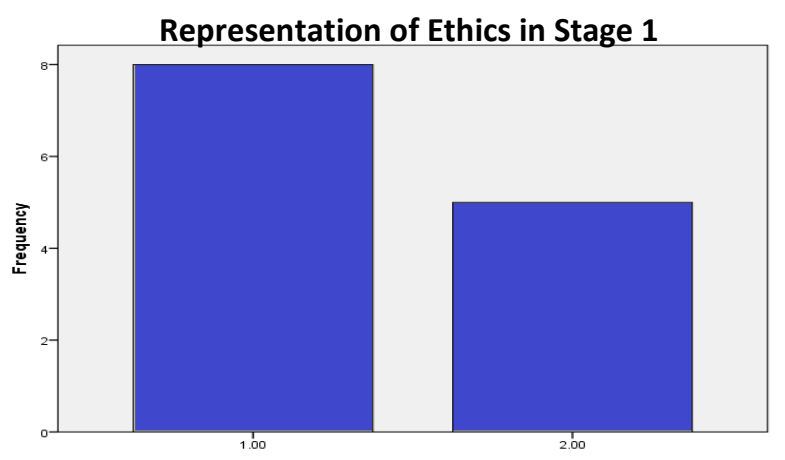

Results of Teacher Respondents

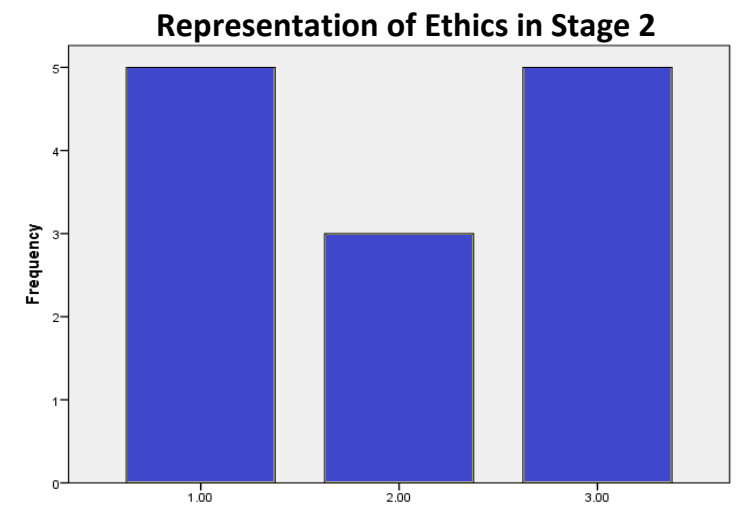

Results of Teacher Respondents

Figure 3.0 Teachers' Responses on Ethics in First Two Stages 
However the responses are high, as can be seen in Figure 4.0 for the last three stages, agreed by students as well.
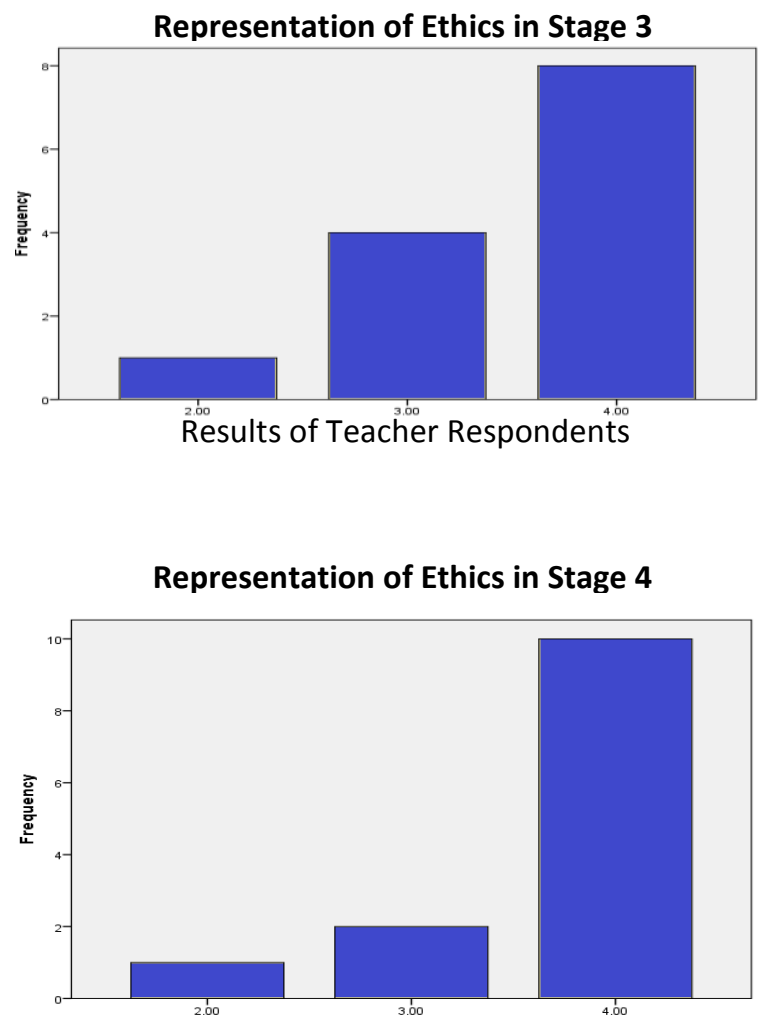

Results of Teacher Respondents

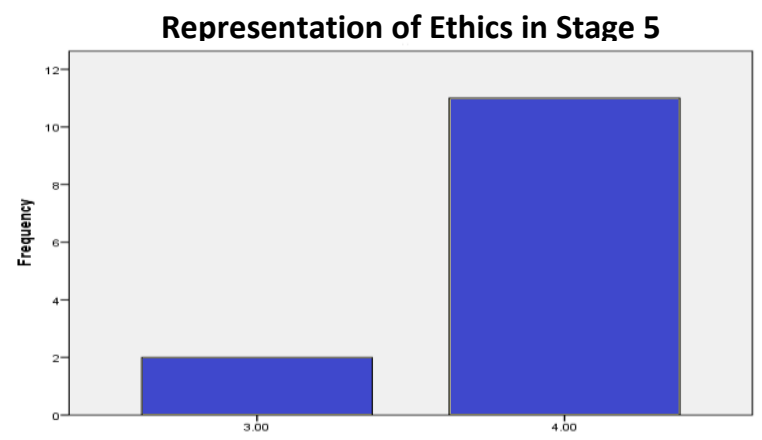

Results of Teacher Respondents

Figure 4.0 Teachers' Responses on Ethics in the Last Three Stages

\section{Inferences:}

It is inferred that abstract aspect such as 'Ethics' or 'Engineer \& Society' (of OBE), the graduate attributes of Washington accord can be imbibed in instructions and there to assessment through the linking of appropriate phrases with domain words in appropriate cognitive structures. This is not possible in traditional methods of instructions.

\section{CONCLUSIONS}

From the above empirical study, it is clearly demonstrated that imbibing phrases/terms pertaining to selective learning outcomes with domain dependent instructional contents and simultaneous assessing has resulted in achieving measurable LOs. The study also proved that, when knowledge and cognitive structures are scientifically and logically designed and administered under OBE's principles and practices, the attainment of required learning outcomes will be achieved more effectively. The research work and the results, is a clear indicator of the aptness of OBE's principles and recommended practices to attain the required competencies as specified by the accreditation agencies for measuring quality benchmarks.

\section{FUTURE SCOPE}

Most of the Institutions in India have not practised instructions as per outcome-based education. Almost all educators are currently ignorant about how to prepare instructions which integrate core with skill and attitude. Even, the assessment has not been done correctly that measures attitudinal factors. With the results of this study, now, educators have an insight of how to measure attitudinal factors using various phrases and terms that imbibe factors leading to attainment of complete attributes for an Engineer.

\section{REFERENCES}

[1] Mathew, Bruce and Sambanthan, Gnana T Sambanthan, (2018), "Prospective Avenues of Continuous Formative Assessments for Facilitating Outcome Based Education in Kerala: A Comparative Study", International Journal and Scientific Innovation (URSI), Vol. V, Issue IX, Sept. 2018. pp:116-120.

[2] Mathew, Bruce and Sambanthan, Gnana $\mathrm{T}$ Sambanthan, (2019), "Outcomes Based Technique for Measuring Critical Thinking Ability on Computer Science and Engineering Students: An Experimental Study", International Journal of Engineering and Advanced Technology (IJEAT), Vol. 8, Issue 6, Aug. 2019, pp:4673-78

[3] Mathew, Bruce and Sambanthan, Gnana T, (2020), "Significance of Contemporary Core Logics for Measuring Learning Outcomes in Computer Science and Engineering", International Journal of Recent Technology and Engineering (IJRTE), Vol. 8, Issue 6, March 2020, pp:3587-3590.

[4] Carriveau, Ronald S (2016), "Connecting the Dots. Developing Student Learning Outcomes and OutcomesBased Assessments", Second Edition, Stylus Publishing House, Sterling, Virginia, USA, 2016

[5] Driscoll, Amy, and Swarup Wood (2007), "Developing Outcomes-Based Assessment for Learner-Centred Education: A Faculty Introduction", Sterling series, VA, Stylus Publishing.

[6] Gnana Sambanthan, T and Sivasankar, P (2018), "Self- 
Regulated Concurrent Practicing Work Material", NITTTR, Chennai 600 113, India

[7] Graduate Attributes (1989), Washington Accord Guidelines: Extracted Dec. 2019, from http://www.ieagreements.org/ GradProfiles.cfm

[8] Haidar M. Harmanani (2017), “An outcome-based assessment process for accrediting computing programmes", European Journal of Engineering Education, 42:6.

[9] International Engineering Alliance (2015), “A History of the International Engineering Alliance and its Constituent Agreements: Toward Global Engineering Education and Professional Competence Standards", International Engineering Alliance, Wellington, New Zealand, Version I, 2015.

[10] Jonassen, D and Tessmer, M (1997), “An OutcomesBased Taxonomy for the Design, Evaluation, Research on Instructional Systems", Training Research Journal, No.2, 1997.

[11] Karen E. Hinton (2012), “A Practical Guide to Strategic Planning in Higher Education", Society for College and University Planning, Ann Arbor, MI, USA, 2012

[12] Marki, P. L. (2012), “Assessing for Learning: Building a Sustainable Commitment Across the Institution", Sterling series, VA, Stylus Publication.

[13] Marzano, R. J and Kendall, J. S (2007), "The New Taxonomy of Educational Objectives", 2nd Ed. Corwin Press, SAGE Publications, CA, USA, 2007.

[14] Merrill, David M. (2007), “A Task Centred Instructional Strategy', Journal of Research on Technology in Education, Vol. 40, No. 1, pp:5-22.

[15] NPE, (2017), K. Kasthurirangan committee, https://mhrd.gov.in/sites/upload_files/mhrd/files/Draft NEP 2019_EN_Revised.pdf Extracted Nov 2018.

[16] Shamsul Muhamad, Zarina Tukiran, Rafizah Mohd Hanifa, Afandi Ahmad, Mohamad Md Som (2012), “An Evaluation of Assessment Tools in Outcome-based Education: A Way Forward", 2012, pp:336-343

[17] Sharma, B.A.V, (1988),"Research Methods in Social Sciences”, S. Chand \& Co. New Delhi, India, 1988.

[18] Sue Bloxham (2016), “Assessing Assessment: New Developments in Assessment Design, Feedback Practices and Marking in Higher Education", Routledge, Ed. Heather Fry, Steve Ketteridge and Stephanie Marshall, London, pp:107-122.

[19] Van der Horst, and McDonald, R, (1997), “OBE. A Teacher's Manual”, Pretoria, Kagiso, 1997, pp:10-11. 